RESEARCH REPORT

\title{
DEVELOPING PROFICIENT LITERACY SKILLS IN CHILDREN WITH BILATERAL PROFOUND SENSORINEURAL HEARING LOSS
}

\begin{abstract}
Objective

By 6 years, typically developing children have adequate reading/reading comprehension, and writing skills. Per evidence-based research, phonological development is a pre-requisite to literacy skills as shown in the growth of receptive/expressive language modalities. Hypothetically, children develop phonological skills mainly through listening unlike children with congenital hearing impairment (HI), who lacks language and acquisition of phonological skills prior to literacy. This study aims to establish a computer-based program called Articulation, Language and Literacy Program (ALLP), following Aural-Oral Approach in children with $\mathrm{HI}$ to develop literacy.
\end{abstract}

\section{Method}

Phonological skills were introduced through the program to 10 children with sensorineural hearing loss targeting areas of articulation, language, and literacy skills, all of whom received early intervention through binaural hearing-aids or monaural cochlear implant. This program facilitated sound-word associations required for reading, simultaneously correcting production of speech, and developing lexical skills. Auditory training was mandatory through all stages of literacy development. Verbal responses and listening skills for speech sounds were recorded on weekly basis with individually tailored assessment tools. Generalization of therapeutic skills was facilitated through handouts given to parents.

\section{Conclusion}

This study reveals that early intervention is critical to language development and literacy skills, leading to academic success of children with hearing impairment in the mainstream academic environment.

\section{Keywords}

Profound Sensorineural Hearing Impairment, Early Intervention, Phonological Development, Metalinguistic Skills, Language Acquisition, Reading.

\section{Amina Asif Siddiqui}

Asst. Prof.

Principal

CSLHS

Ziauddin University

amina.siddiqui@zu.edu.pk

Verda Nadeem Butt

Student SLT

CSLHS

Ziauddin University

Verda.butt92@gmail.com

\section{Saamia Bilal Khan}

Senior Lecturer

CSLHS

Ziauddin University

saamiabilalkhan@gmail.com
[Siddiqui AA, Butt VN, Khan SB, Developing Proficient Literacy Skills in Children with Bilateral Profound Sensorineural Hearing Loss. Pak. j. rehabil; 2015;4(1):15-22] 


\section{INTRODUCTION}

The objective of this empirical, longitudinally conducted qualitative study was to successfully establish a methodology for developing language, phonological and literacy skills in children with congenital bilateral profound sensorineural hearing loss' ${ }^{\prime}$, through a structured instructional model of the Articulation, Language and Literacy Program (ALLP); which would promulgate children with hearing impairment into the mainstream of education with hearing peers.

\section{Background}

Language development is one of the most complex skills acquired by the human baby, which grants him supremacy over other living beings, in our world. Piaget states that every baby must fulfill the cognitive pre-requisites to achieve this feat ${ }^{2}$. The most essential among these is a well functioning auditory apparatus, for the input of all verbal language symbols. The fetus hears the mother's voice at an intensity of $70 \mathrm{~dB}$ since the $25^{\text {th }}$ week of gestation ${ }^{3}$. The baby's awareness of the abundant sounds in his surroundings begins at birth; and, by his first birthday he learns to localize them, and can also identify/discriminate amongst the gross and speech sounds that he hears. Additionally the sense of vision compliments the sense of hearing in receiving information, but is not sufficient alone for the acquisition of language in babies ${ }^{4-6}$. The baby must possess a normally developing and functioning neuro-motor apparatus, so that the sounds he hears are decoded correctly; whilst the sounds he makes (words that he shall speak) are encoded and sent to the speech organs to be uttered. He needs a well developing speech mechanism with normal intellectual growth. To exploit these pre-requisites the baby needs a stimulating environment with ample social and verbal exchanges amongst the baby and his caregivers, thus acquiring his mother tongue or native language ${ }^{7}$.

During the process of language acquisition the human baby is able to monitor his own vocalizations and match them to those of his caregivers through the auditory feedback loop; which is responsible for the development of metalinguistic skills in the early years 8.9 . This is particularly evident when the baby is acquiring the sounds of his language. The speech errors during this period, which are called natural or phonological processes, exhibit the baby's self correction as he progress from a phonologically simple version of a word to its actual form example; "spoon" may be spoken as "poon" in the early years. Speech language maturation is usually achieved by the age of 6 chronological years, in typically developing children.

Literacy skills ${ }^{10,11}$ constitute the two modalities of language that little children acquire successive to verbal communication skills. Literacy entails the encoding of written symbols of a language with their respective sounds, and their systematic and organized combination in words. The act of reading comprehension originates with the learning of meaning of these symbols through the act of reading.

Children with profound hearing impairment have difficulty acquiring verbal communication skills the natural way, unless they receive appropriate binaural amplification within the first year of life, which is usually not the case in developing countries. Pakistan too, has a long way to go before early intervention of hearing loss becomes a norm. Thus acquiring literacy skills for children with hearing impairment at par with their hearing peers becomes a challenge.

\section{METHODOLOGY}

This article manifests the implementation of the Articulation, Language and Literacy Program (ALLP), for learning of all language modalities by 10 children, with hearing impairment. It is a computer based program ${ }^{12,13}$, which is based upon studies of technology based intervention ${ }^{14}$ in schools for typically developing children; that have shown enhanced attention control and learning in children being taught how to read using phonic and alphabet soft ware and applications with children in the preschool years. The ALLP must be used by adults with children, in unison with reading activities that utilize alphabet and picture cards as well as worksheets.

\section{Inclusion Criteria}

The children who had congenital bilateral severe-profound (90dB or above) sensorineural hearing impairment were included.

- Children from bilingual homes, where English (L2) ${ }^{15}$ was the dominant language but Urdu was the native language (L1).

- Early intervention was a strict criterion, with the children receiving appropriate amplification by the age of 2 years, which was used consistently and regularly.

- Children were using binaural hearing aids or monaural cochlear implants ${ }^{16,17}$.

\section{Exclusion Criteria}

- Most children were excluded on the basis of lingual set-up at home.

o Children exposed to more than two languag es.

o Children having two languages at home but neither of the two was English.

o Children exposed to Udru (L1) and English (L2); where Urdu was the dominant language.

- Children with hearing threshold of less than $85 \mathrm{~dB}$ in any one ear. 
- Children given intervention after their second birthday.

- Children with monaural hearing aids.

- Children were inconsistent for therapy and/or did not use the amplification device regularly and consistently

- Children were exposed to natural gestures or signs, to facilitate communication ${ }^{18}$.

\section{Rationale of the ALLP for Children with Hearing Impairment}

- The basis of ALLP was the acquisition of phonological skills in typically developing children. However since the children in this study had a bilateral profound sensorineural hearing loss, early intervention was given great emphasis, because it ensured the development of good listening skills through auditory training exercises done very frequently throughout the program. Therefore it was incumbent that all the children that were taught to read through the ALLP had been given appropriate amplification devices in both ears, within the first two years of life; and they were used regularly and consistently.

- The Aural-Oral approach ${ }^{19}$ that was used with the children in this study, stresses upon natural communication, wherein the auditory channel is the primary mode of input for all verbal information, with an oral or verbal mode of output. Here, natural communication is characterized by the child listening to the speaker as well obtaining information through facial expressions and body language. The speaker's utterances must have linguistic suitability with respect to the child's hearing age and language age. Hearing age is calculated from the time the child begins to wear the amplification devices consistently; while language age is defined by the Brown's stages of language development ${ }^{20}$ that draws a correlation between accomplishment of language milestones and the chronological age of the child.

- The ALLP was implemented through hi-tech computer based learning tools ${ }^{21}$, in the English language(L1), with then ten children who fulfilled the above inclusion criteria, and were observed over a minimum period of 5 years (2-7 years) or more. All these participants were enrolled in mainstream schools where English was the medium of instruction. The aural-oral mode of communication was used with them; consisting of regular individualized speech-language therapy and auditory training conducted by the speech language therapist (SLT); who was also the primary investigator (PI) in this study. At the time of enrollment into this study the children's parents were encouraged to read aloud to their child in order to inculcate a pleasurable habit of reading. Reading aloud to the children improved their listening skills and also helped them in achieving better lexical and morph syntactical skills ${ }^{22}$ in their language. Most important- ly this habit led to enhanced development of pre literacy skills in the participants. The SLT provided a methodical regimen of carryover of therapeutic goals to the parents and the child's teachers, to help establish the learnt language and literacy skills. In school the class teacher usually helped the child develop his language and literacy skills, throughout the primary education years hence her role was vital to this program. All data was systematically collected in datasheets by the SLT during the therapy sessions thereby recording the child's progress across the period of study. All the data of each child was maintained in files of a computer, as well as in hard copy format, describing the rate of progress from one stage of reading to another.

- Each stage of the ALLP program was explained to the parents, who transferred the tasks learnt during the therapy session, at home. Transfer and carryover assignments included reading from picture books, coloring and painting which were also given to maintain the pleasure of reading. The speech language therapist gave the children worksheets with exercises and activities such as matching pictures and words as well as words with words; and the pasting of alphabets (sounds) in the blank spaces, and matching words together. The therapist also communicated with the school on a regular basis to facilitate the acquisition of good reading skills in these children with hearing impairment.

- The ALLP maintained a hierarchy of tasks named as 'Stages,' where the complexity of reading exercises progressed from one stage to the next, and the child had to achieve a mastery of at least $70 \%$ in each stage to move further to the next one. Auditory training was the most important aspect of each stage since metaphonological ${ }^{23}$ skills depend upon the child's auditory discrimination at the sound, word, phrase and sentence levels.

\section{Stage 1: Introduction to phonic skills through the computer based ALLP for HI}

The English alphabet of 26 letters was used in the study, with each letter representing a phoneme. Each alphabet was associated with 2-4 words having the sound/phoneme in the initial position, thereby stimulating the child's metalinguistic ${ }^{24}$ and metaphonological skills. (See figure 1) The alphabets were grouped into two broad categories of 'vowels' and 'consonants' and further divided into 5 subgroups. The phonemes and words were spoken by the speech language therapist in naturally loud voice; sitting beside or behind the child, within a distance of a meter. Although the SLT did not restrict visual input if the child looked up at the therapist, lip reading or speech reading was not given emphasis per se. The child spoke the words in imitation of the SLT and all responses were recorded as 'imitation,' or 'spontaneous response;' because both type of responses were indicative of the child's listening skills, as well as the development of meta- 
linguistics. Knowing the child's speech production as either an imitation of the heard word or a spontaneous production indicated his/her auditory comprehension which was essential to the development of phonemic and lexical skills, as well as literacy. The child's responses were recorded on weekly basis in a record form drafted for the ALLP. (See figures: $2 a$ \& 2b) Thus these stimuli also served the function of a speech test, with auditory discrimination, recognition and comprehension of stimuli being assessed ${ }^{25}$, recorded and maintained for later reference. The instances of the child's spontaneous use of words indicated the lexical development over time.

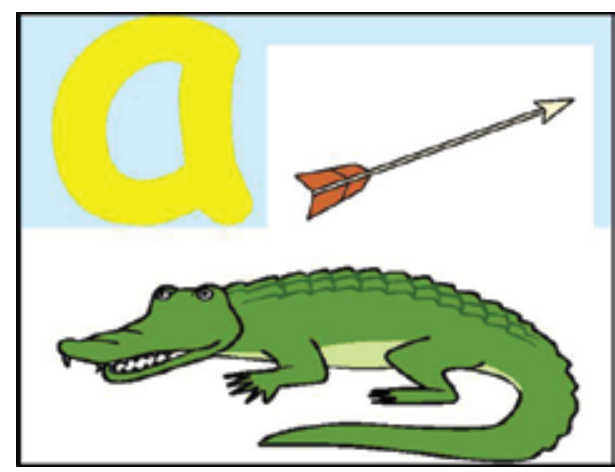

Figure 1

Stage 2: Developing phonological awareness through auditory training and reading ${ }^{26}$

The vowels and consonants of the English alphabet were divided into 5 subgroups in which they were carefully categorized on the basis of phonological development in children with the hierarchy of their acquisition in a child's early and later verbal repertoires. Additionally the consonants in the subgroups were auditorily and visibly different from one another, facilitating the development of letter-sound associations. Moving through sub groups 1-5 meant moving from easy to difficult production of sounds. The sub groups were as follows:

sC 1: $a, b, m, l, o$,

SC 2: c,e,f,p,n

SC 3: $t, i, g, h, u$

SC 4: $d, j, k, s, v$,

SC 5: r,z, q.

The two diphthongs $w, y$ and the blend $x$ were not added into any group. Long vowels were taught after the child had successfully learnt to read and form CVC words. (See figure 2b)

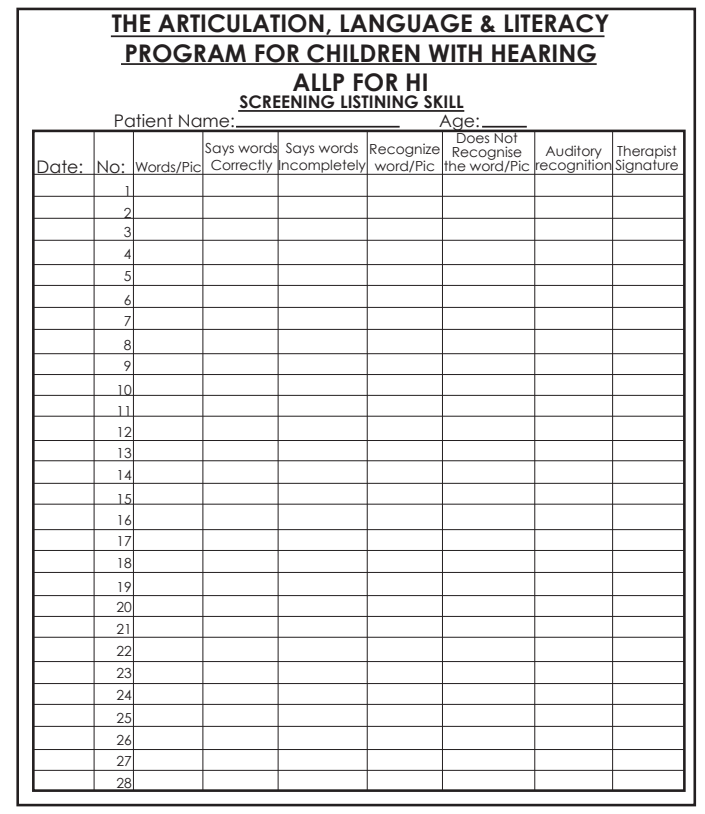

Figure 2a

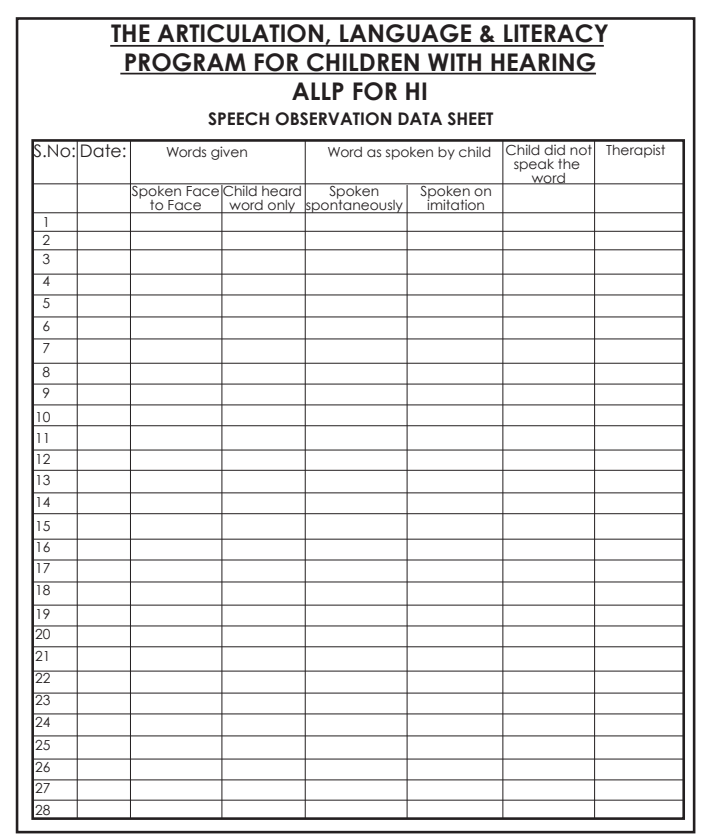

Figure $2 b$ 


\section{Stage 3: Auditory training for reading or develop- ment of literacy}

The child was shown a series of 10 slates with 4 CVC words on each. These words on each slate had different consonants and vowels (i.e. no sound was repeated amongst these words), and the child was asked recognize and point to the words as they were read aloud by the SLT. This task stimulated the child's auditory and visual perception; as it is only natural for human beings to use the information gathered through listening and vision for optimal processing (decoding) in the higher centers of the brain. The child's responses were recorded in the assessment Performa, as immediate response, when the child recognized and pointed to the word on hearing it just once from the SLT. All subsequent responses were marked as a no response, and the exercise was repeated, till the child recognized each word on hearing it just once.(See figure 3)

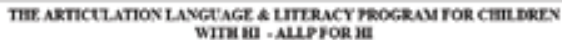 \\ ran

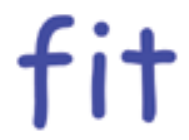 \\ sum

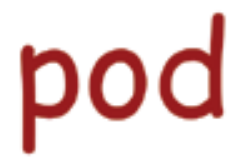

Figure 3

Stage 4: Formation of CV, VC and VCV syllables. As the child learnt to decode a CVC word, a speech drill of, nonsense syllables was carried out to teach him to make a CVC word himself. A computer based program was used in which the child used the keyboard to write the syllable and then read it aloud. The same was done using small cards with a letter written on them. Each consonant and vowel was articulated phonetically, which helped the child read the syllables with ease. The CV syllables were first taught with continuant consonants /I/ /m/, /n/, /f/, /s/ and diphthong /w/; followed by the VC and VCV syllables. The rest of the consonants were introduced in the drill after the child had learnt to read these syllables. (See figure: 4a, 4b, 4c)

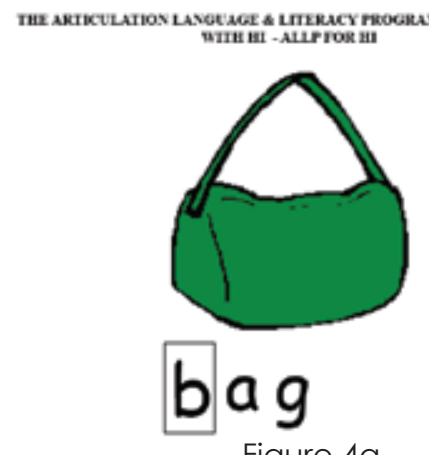

Figure 4a

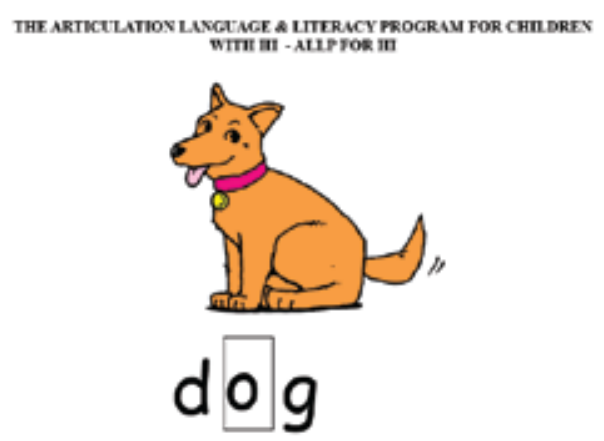

Figure $4 b$

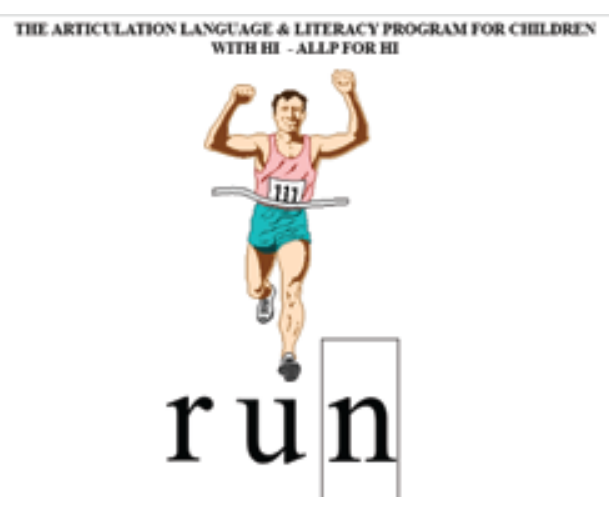

Figure 4c

\section{Stage 5 : Filling in the Vowel, reading CVC words} and auditory training

The child was shown a picture on the computer screen with part of the word written below it; e.g. pin was written as p_n. The speech language therapist wrote two vowels /i/ and /o/ on a piece of paper, and spoke the target word naturally without any stress on the missing vowel (no exaggeration of lip movements as per the rationale of the aural-oral methodology), and the child was allowed to look up at the therapist as she spoke. The child had to auditorily discriminate and identify ${ }^{27}$ the missing vowel from among those written on the sheet of paper and fill in the missing sound (vowel) in the word; then read the word aloud to the SLT. The words were chosen randomly and not from the child's lexicon; with the pictures facilitating the child in comprehending and conceptualizing the word if it was new to him. As the child became dexterous in filling in the missing vowel from amongst /o/ and /i/, the vowels /a/, /u/ and /e/ were added to the group for completing the word/s. 
Great emphasis was given to listening tasks in this stage, teaching the child to discriminate between minimal pairs auditorily e.g. pin, pan and pen. Activities of finding words that sounded similar were conducted with the child, e.g. when pod was the spoken word the child would match the word rod to it from amongst the words red - rod. (See figure 5)

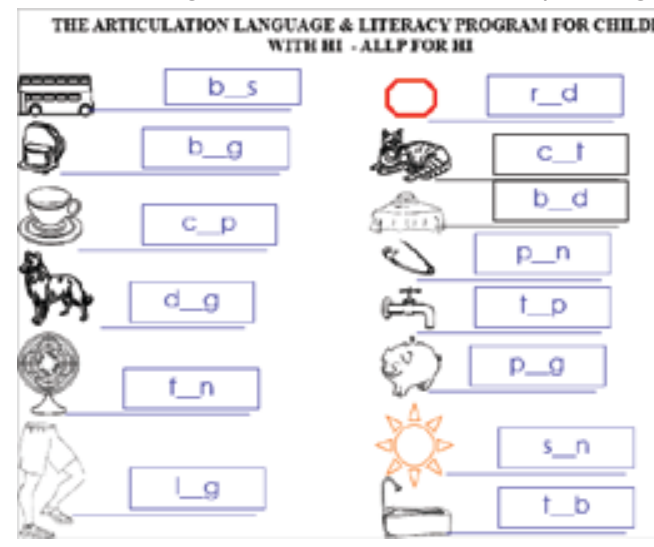

Figure 5

Stage 6: Filling in the initial consonant, reading CVC words, with auditory training ${ }^{28}$

This stage was similar to stage 5. At first the child was taught to focus up on the initial position of the word and was asked to identify the consonants in the initial position through a listening exercise. Then six consonants from amongst stops (any three from /b/, $/ \mathrm{p} /, / \mathrm{c} /, / \mathrm{g} /, / \mathrm{t} /, / \mathrm{d} /$ ), and continuants (any three from $/ \mathrm{l} /, / \mathrm{m} /, / \mathrm{n} /, / \mathrm{s} /, / \mathrm{z} /, / \mathrm{f} /, / \mathrm{dz} /, / \mathrm{t} \otimes /, / \mathrm{r} /$ ), were written on a piece of paper to begin with, and the child was to discriminate and identify the correct sound from amongst the letters written on the paper and complete the word.

Again, an auditory training exercise with minimal pairs e.g. pat - bat, helped the child improve the recognition of consonants. (See figure: 6)

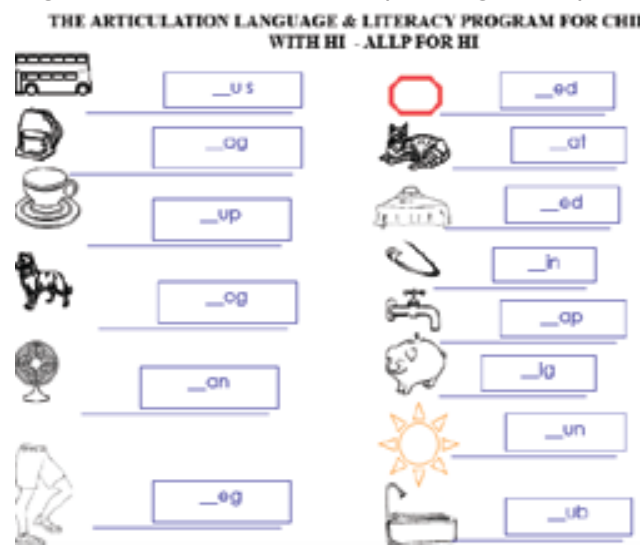

Figure 6
Stage 7: Filling in the final consonant reading CVC words, with auditory training

This stage was exactly the same as stage 6 , with the exception of the consonant here being in the final position. It culminated with listening exercises for minimal pairs, this time discriminating the consonant in the final position. E.g. bat - bad.

\section{Stage 8: Reading phrases \& sentences made with CVC words, with auditory training.}

The last stage of this program was manifest in the child being able to read phrases and sentences constructed with CVC words, and discriminating amongst four sentences, written on a page. E.g. A big bat, A hat on a mat, A fat cat, A bat and a rat. (See figure 7)

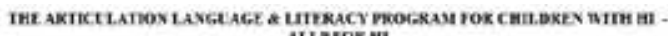
MLLFFК HI

\section{A hat for a cat}

\section{Pat is fat A flat bat}

The rat sat on a mat

Figure 7

\section{DISCUSSION}

The ALLP is a structured series of tasks that is easy to use with children in the preschool years because it not only stimulates the development of language but also maintains their interest and attention through the activities, which is essential for young children. The documentation of the child's responses in the given recording sheets is easy to use and refer to; which facilitates the SLT in planning the subsequent goals. The emphasis on auditory training activities through the 8 stages of ALLP provides stimulus for the development of metalinguistic and metaphonological skills which are necessary for the development of reading skills in the early years.

\section{CONCLUSION}

The 10 children in this study were enrolled in mainstream schools where they successfully indulged in all academic assignments at par with their hearing peers. The ALLP provided them with enhanced lexical skills during the initial years of therapy and helped them become proficient readers through their academic tenure with better metalinguistic and metaphonological skills. Further research using the ALLP is underway, in a quantitative longitudinal study. 


\section{RECOMMENDATIONS}

Pre-school children must be given the opportunity to learn language in all its four modalities, through environmental stimulation from parents, and all care givers. Utilization of computer based technology is strongly recommended for the acquisition of literacy skills as it stimulates cognitive and linguistic abilities of the child, giving an impetus to learning everything taught. The cause and effect relationship provided by the tools(mouse and key board) used to perform the activity; and the activities themselves are useful in maintaining the attention of the child, however the SLT must maintain full control over the child's performance till the child masters their use. Parent training is an important consideration when working with children having profound hearing loss, as they shoulder the responsibility of providing language stimulation through daily activities, and through reading stories aloud to the child in order to ensure that their child enrolls in mainstream school for a successful academic career.

\section{REFERENCES}

[1] Rajasekar S, Chinnathambi V, P. Philominathan. Research Methodology. New York: arXiv.org;2006. Available from: http://arxiv.org/abs/physics/0601009v3.

[2] Major, E, Bernhardt, B. Metaphonological skills of children with phonological disorders before and after phonological and metaphonological intervention; International Journal of Language \& Communication Disorders; Volume 33, Issue 4: pages 413-444.

[3] Chavda U. Interesting Research : Sound \& Womb; 2009, Available from https://www.linkedin.com/pulse/20140809034436-75260595-interesting-research-sound-womb.

[4] Mckay A. What is language Acquisition? - theories, stages and quiz. 2003. Available from: http://study.com/academy/lesson/what-is-language-acquisition-theories-stages-quiz.html

[5] Green E. Language Acquisition (Ch. 6/ lesson 7) [published video lecture on the Internet], 2003-2014, Psychology 101: Intro to psychology. Available from: http://study.com/academy/lesson/language-acquisition.html

[6] Roundy L. Stages of Language Development: Pre-Linguistic and Symbolic Language [published video lecture on the Internet]. 2003-2014, Psychology 103: Human Growth and Development.study. com. Availablefrom: http://study.com/academy/lesson/stage $s$ - of - I a n g u a $\mathrm{g}-\mathrm{d}$ e $v$ e I o p ment-pre-linguistic-and-symbolic-language.html

[7] Zoltan Dorneyi; Attitudes, Orientations and Motivations in Language Learning: Advances in Theory, Research and Applications; 2010. Available from http://wiki.zirve.edu.tr/sandbox/ groups/prep/wiki/ 5 f 53 f / a t tachments/225ca/Dornyei\%20(2010).pdf
[8] Nittrover S, Burton LT. The role of early language experience in the development of speech perception and phonological processing abilities. Journal of Communication Disorders. 2010; 38(1):29-63.

[9] Karmiloff-Smith A. From meta-processes to conscious access: Evidence from children's metalinguistic and repair data Cognition. 1996; 23(2): 95-147.

[10] R. Owens, Language Development - An Introduction 8th edition, Pearson, 2012

[1 1] Gleason J.B. The Development of Language. 3rd Edition. 1989, Mcmillan Publishing Company.

[12] Thao Lê, Quynh Lê, Using Computers To Promote Literacy Development, Chapter 5, ISBN 978-1-60021-699-2; 2007; Available online from : http://core.ac.uk/download/pdf/12177211.pdf Roschelle, RJ, Roy,DP, Hoadley, CP, Gordin, DN,

[13] Means, BM, Changing How and What Children Learn in School with Computer-Based Technologies; The Future of Children; Vol. 10, No. 2, Children and Computer Technology (Autumn Winter, 2000), pp. 76-101; Princeton University; DOI: 10.2307/1602690; Available online from : http://www.jstor.org/stable/1602690

[14] Wolgemuth, J, Savage,R, Helmer, J, Lea,T, Harper,H, Chalkiti,K, Bottrell, C, Darwin, C, Abrami, P, Using computer-based instruction to improve Indigenous early literacy in Northern Australia: A quasi-experimental study ; Australasian Journal of Educational Technology 2011, 27(4), 727-750; Available from http://www.ascilite.org.au/ajet/ajet27/wolgemuth.pdf

[15] Guiberson M, Bilingualism aids new skills among the hearing impaired, Audiology Worldnews, [Serial on the Internet], 2014, Available from : http://www.audiology-worldnews.com/images/stories/archives/science/Bilingualismaids.pdf

[16] Kooshalnagar, P, et al, Infants and Children with Hearing Loss Need Early Language Access, J Clin Ethics. [serial on the internet], 2010, PMC 2011, 21 (2): 143-154, NIHMS25728. Available from : http://www.ncbi.nlm.nih.gov/pmc/articles/PMC3072291/

[17] Advanced BionicsCorporation Valencia, CA 91355, Hearing with Two Ears: Technical Advances for Bilateral Cochlear Implantation; 2004, Available from : https://www.advancedbionics.com/content/dam/ab/Global/en_ce/documents/candidate/AB_Tech_Advances_for _Bilateral_Cochlear_Implantation_article.pdf

[18] Gravel SJ, O'Gara J, Communication Options For Children With Hearing Loss, Mental Retardation And Developmental Disabilities Research Reviews [serial on the internet], 2003, 9: 243-251 Available from : http://Isl.usu.edu/files/Gravel-ComunicationOptions.pdf

[19] Nelson, G, Communicating with the Hearing Impaired Child: The Aural - Oral Approach; Hearing Volume 5, Communication Skill Builders, 1990; Available online from: http://www.csun.edu/ hfedu009/innovations/hand- 
$\circ u \dagger \mathrm{s} / 00604025 / \mathrm{c} \quad 0 \mathrm{~m}$ municating_with_the_hearing-impaired_child.p df

[20] R. Owens, Language Development - An Introduction 8th edition, Pearson, 2012

[21] Bloom, S, Technologic advances raise prospects for a resurgence in use of auditory training; The Hearing Journal, Volume 57 - Issue 8 - p 19-20,22-24; 2004; Available from : http://journals.Iww.com/thehearingjournal/Citation/2004/08000/Technologic_advances_raise_ prospects_for_a.4.aspx

[22] Weigel, DJ, Martin, SS, Bennett, KK, Contributions of the home literacy environment to preschool-aged children's emerging literacy and language skills; Early Child development and Care, Volume 176, Issue 3-4, 2006; Available from : http://www.tandfonline.com/doi/abs/

[23] Hodgson, J; The Status of Metalinguistic Skills in Reading Development; Journal of Learing Disability; February 1992 25: 96-101; Available online from : http://ldx.sagepub.com/content/25/2/96.full.pdf+html

[24] Harris, PL, The cognitive Pre Requisite to Language; Voulme 73, Issue 2, Pages 187 - 195;
British Journal of Psychology, 1982, published online 2011; Available online from : http://onlinelibrary.wiley.com/doi/10.1111/j.2044-8295.1982.tb01801.x/pdf.

[25] Sweetow, Robert W.; Sabes, Henderson, J, The Need for and Development of an Adaptive Listening and Communication Enhancement (LACE ${ }^{\mathrm{TM}}$ ) Program; The American Academy of Audiology; Volume 17, Number 8, September 2006, pp. 538-558(21); Available from : http://www.ingentaconnect.com/content/

[26] Mol, SE, Bus, AG, De Jong, MT, Interactive Book Reading in Early Education: A Tool to Stimulate Print Knowledge as Well as Oral Language; Review of Educational Research; vol. 79 no. 2979-1007; 2009; Available from: http://rer.sagepub.com/content/79/2/979.short

[27] Tye-Murray, N, Foundations of Aural Rehabilitation; 4th Edition, Cengage Learning, 2015.

[28] Schoepifin, RJ, Back to Basics: Speech Audiometry; 2012, Available online from: http://www.audiologyonline.com/articles/back-to-basics-speech-audiometry-6828 